\title{
Which start is faster in finswimming?
}

\author{
Vasileios Stavrou $^{1,2}$, Vasileios Voutselas $^{1}$ \\ ${ }^{1}$ School of Physical Education and Sports Science, University of Thessaly, Karies, Trikala, Greece. \\ ${ }^{2}$ Laboratory of Cardio-Pulmonary Testing, Department of Respiratory Medicine, University of Thessaly, Larissa, Greece.
}

\begin{abstract}
Finswimming is a sport of speed practiced on the surface or underwater. The purpose of this study was to investigate the difference between two finswimming starts: the grab start (Gs) and the research start with hands on metatarsals (HMs). Fourteen well training young male finswimmers participated in our study and assessment the flight, the angle of entry, the angle of knee and the performance at the first $15-\mathrm{m}$. The results show differences between the two starts in the flight [Gs: $130.3 \pm 9.1$ vs. HMs $\left.136.2 \pm 7.9 ; \mathrm{t}_{(13)}=-6.08, \mathrm{p}=0.000\right]$, in the angle of knee [Gs:

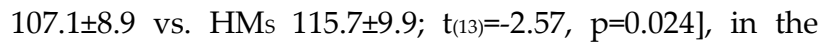
angle of entry [Gs: $55.4 \pm 7.4$ vs. HMs $52.6 \pm 5.2 ; t_{(13)}=2.71$, $\mathrm{p}=0.018$ ] and at the first $15-\mathrm{m}$ performance [Gs: $5.7 \pm 0.5 \mathrm{vs}$. HMs $5.4 \pm 0.3 ; \mathrm{t}_{(13)}=4.17, \mathrm{p}=0.001$ ). This study demonstrates that the HMs is able to improve the parameters during entry which related with faster swimming.
\end{abstract}

Keywords. Finswimming, start, young athletes.

\section{Introduction}

$\mathrm{F}$ inswimming is a sport of speed practiced on the surface or underwater, in which performance is based on whole-body oscillations (Gautier et al., 2004). The start in finswimming it is same like as a swimming grab start because of the use monofin. The start divided into five temporal phases: ready, pulling, detachment, flight and entry (Costill et al., 1992). The success of startup depends on rapid succession of a movementphase to another.

The purpose of this study was to investigate the difference between two finswimming start (Grab start: Gs, Figure 1; Research start with hands on metatarsals: HMs, Figure 2) in flight, entry, angle of the knee at the stage of ready and the performance on the first 15-m. We hypothesized that the different start could affect the finswimming performance.

\section{Methods}

\section{Participants}

Fourteen well training young male finswimmers, from the local finswimming club, participated in our study (Table 1). Inclusion criteria were not to have injuries in lower limbs and training age in finswimming $>3$ yrs. The study was conducted according to the Helsinki declaration for use in Human subjects ( $\mathrm{N}^{\circ}$ of Ethical Committee; 25/2.2.2011). All the participants' parents written consent.

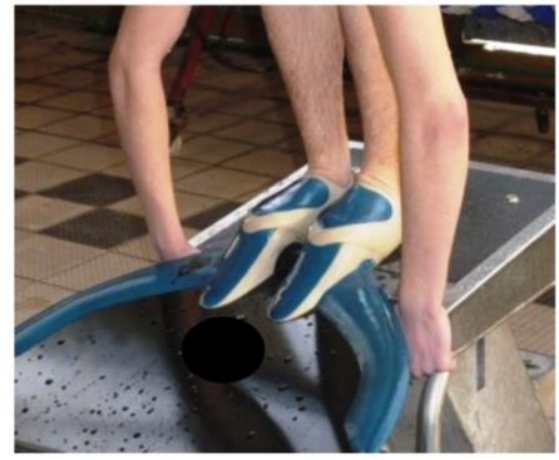

Figure 1. Grab start (Gs).

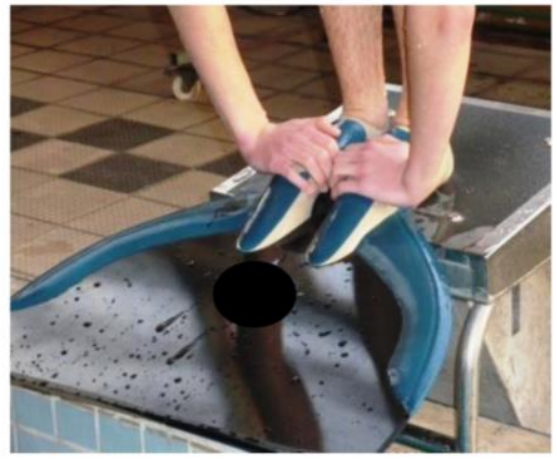

Figure 2. Start with his hands on metatarsal (HMs). 
Table 1

Athlete's characteristics.

\begin{tabular}{lc}
\hline Variables & Mean \pm SD \\
\hline Age $(\mathrm{yrs})$ & $16.5 \pm 0.9$ \\
Height $(\mathrm{cm})$ & $167.2 \pm 4.0$ \\
Height with his hands in an elevation $(\mathrm{cm})$ & $212.2 \pm 4.0$ \\
Training age $(\mathrm{yrs})$ & $4.5 \pm 1.2$ \\
Body Mass Index $\left(\mathrm{kg} / \mathrm{m}^{2}\right)$ & $21.3 \pm 3.0$ \\
Body Surface Area $\left(\mathrm{m}^{2}\right)$ & $1.3 \pm 0.1$ \\
Body mass $(\mathrm{cm})$ & $59.5 \pm 7.2$ \\
Body fat $(\%)$ & $12.2 \pm 4.8$ \\
Sit and reach test $(\mathrm{cm})$ & $28.0 \pm 3.0$ \\
Leg length $(\mathrm{cm})$ & $90.2 \pm 0.4$ \\
Isokinetic $\mathrm{knee} \mathrm{extensor} \mathrm{torque}(\mathrm{N} \bullet \mathrm{m})$ & $159.6 \pm 9.8$ \\
Squat jump $(\mathrm{SJ})(\mathrm{cm})$ & $29.8 \pm 1.3$ \\
\hline
\end{tabular}

\section{Procedures}

Prior to the test procedures were measured the anthropometric characteristics, the percentage of body fat (7 skinfold points measurement, Harpenden, UK) (Norton et al., 1996) and the flexibility by sit and reach test (Cochrane \& Stannard, 2005). The height of leg was measured from the grater trochanter to the lateral malleolus (Norton et al., 1996). For the isokinetic assessment of flexor and extensor muscles of the knee was used isokinetic dynamometer (Cybex Norm). The Jumping ability was measured by the squat jump (SJ) in force platform (Bertec Corp., Worthington, $\mathrm{OH}$ ) (Bosco et al., 1983).

The trials were performed with a difference of 48 $\mathrm{h}$ between them. The trials were performed at a maximal intensity. The athletes performed the garb start (Gs) by three consecutive attempts. Among the efforts was 5 min rest. The start of each effort was made accordance CMAS rules (CMAS, 2013). All participants were used the personal monofin (weight $3 \pm 0.5 \mathrm{~kg}$ ) and all trials was made without snorkel (Figure 1 and 2). All the sessions were performed in a 50-m indoor swimming pool with water temperature at $26 \pm 1{ }^{\circ} \mathrm{C}$ and environmental temperature at $24 \pm 1{ }^{\circ} \mathrm{C}$. The evaluation was made between 17:30 and 18:30 p.m. The tests were performed in random sequence (Gs and HMs) and athletes did not warm-up before the tests.

All trials were record by two GoPro Hero5 Black camera. The first camera was mounted on a fixed point to allow coverage of all efforts and the second was record the angle of knee. The angle of knee was calculated by placed marks on the greater trochanter, lateral condyle of femour and the lateral malleolus. The angle of entry was calculating accordance to constant reference on the surface and the entry of upper limbs. The upper limbs were calculated by placed marks on carpus area, major olekrano and on the area of head of humerus.

The evaluation and analysis of kinematic characteristics and efforts of trials were used by program V1sports Home 2.0 (USA) and software Templo 3.2.166 (Contemplas, Germany). The time performance (time/s) was recorded with a digital handheld chronometer (Cei-Ultrak 499, Cardena, CA, USA).

\section{Statistical analysis}

The Kolmogorov-Smirnov test was used for the normality of the distribution. Paired t-test was used to determine statistically significant differences between variables of two trials. The level of significance was set to $p<0.05$ and the data are presented as mean value and standard deviation (Mean \pm SD). The SPSS 15 statistical package (SPSS inc., Chicago, IL, USA) was used for the statistical analyses.

\section{Results}

The results of two trials showed in Table 2.

Table 2

Results between trials (Mean \pm SD).

\begin{tabular}{lccc}
\hline & Gs & HMs & $p$ value \\
\hline Flight $(\mathrm{cm})$ & $130.3 \pm 9.1$ & $136.2 \pm 7.9$ & 0.000 \\
Entry $\left({ }^{\circ}\right)$ & $55.4 \pm 7.4$ & $52.6 \pm 5.2$ & 0.018 \\
Knee $\left({ }^{\circ}\right)$ & $107.1 \pm 8.9$ & $115.7 \pm 9.9$ & 0.024 \\
Time $0-15 \mathrm{~m}(\mathrm{sec})$ & $5.7 \pm 0.5$ & $5.4 \pm 0.3$ & 0.001 \\
\hline
\end{tabular}

\section{Discussion}

This study increases the knowledge of fin swimming start which is quite weak in the scientific literature. Was investigated the Gs versus $\mathrm{HMs}$ to determine differences between of them accordance to swimming assessment methodology which can be applied in fin swimming (Stavrou et al., 2007).

The finswimmers during the entry meets the same resistances like the swimmers (Vorontsov \& Rumyantsev, 2000) and moreover due to equipment. 
The equipment could be a limitation into performance and an item that affects the evaluation variables. The entry during $\mathrm{HMs}$ was measured higher compare to Gs. The entry in accordance to Maglischo (2003) is around 3 to 4-m in elite swimmers. The HMs is closer to swimmers values although we used heavy monofin. These monofins could have negatively affected the outcome of the motion (Pendergast et al., 2003) and probable following different kinematics pattern modifies muscular activity (Mariona et al., 2010). According to Kong and Haselen [12] the maximum isometric strength of the quadriceps extensor muscles associated with the angle of the knee expressed in 110-120. The angle of knee in HMs was measured closer to average values Kong \& Haselen (2010) compared to Gs (Table 1).The angle of entry, accordance to Maglischo (2003), is $30-40^{\circ}$. Our results releves lower angle of entry with $\mathrm{HMs}\left(52.6 \pm 5.2^{\circ}\right)$ compared to Gs $\left(55.4 \pm 7.4^{\circ}\right)$. The parameters of the length of entry and the angle of entry are closer of average values of swimmers. These results relate to the hands position during start thus increasing the angle of the knee which produces more power (Murray et al., 1980) and swimming faster the first 15m (Table 2).

\section{Conclusions}

This study demonstrates that the HMs is able to improve the parameters during entry which related with faster swimming. The finswimming as a newly sport with weak in the scientific literature, enough research is needed to substantiate new methods.

\section{Conflict of interest}

The authors declare they have no conflict of interest

\section{Ethical approval}

All procedures performed in studies involving human participants were in accordance with the ethical standards of the institutional and/or national research committee and with the 1964 Helsinki declaration and its later amendments or comparable ethical standards.

\section{Informed consent}

Informed consent was obtained from all individual participants included in the study.

\section{References}

Bosco C, Luhtanen P, Komi PV. A simple method for measurement of mechanical power in jumping. Eur J Appl Physiol Occup Physiol, 1983; 50(2): 273.

CMAS, World Underwater Federation. Finswimming Cmas Rules, Version 2010/01, (23/04/10, BOB /SPO/No 26), 2010. [updated 2013 Jan 10] Available at: http://www.cmas.org/comspo/nap/

Cochrane D, Stannard S. Acute whole body vibration training increases vertical jump and flexibility performance in elite female field hockey players. Br J Sports Med, 2005; 39(11): 860.

Costill LD, Maglischo E, Richardson BA. Handbook of Sports Medicine and Science: Swimming. $2^{\text {nd }}$ ed. Blackwell Scientific Publications: London; 1992.

Gautier J, Laurent B, Zanone PG, Watier B. A kinematic study of Finswimming at surface. J Sports Sci Med, 2004; 3(2): 91.

Kong PW, Haselen J. Revisiting the influence of hip and knee angles on quadriceps excitation measured by surface electromyography. International Sport Med Journal, 2010; 11(2): 313 .

Maglischo E. Swimming Fastest. $2^{\text {nd }}$ ed. Human Kinetics: Canada; 2003.

Mariona K, Guillaume G, Pascale C, Charlie B, Antonb S. Muscle activity during fin swimming. Procedia Engineering, 2010; 2(2): 3029-3034.

Murray MP, Gardner GM, Mollinger LA, Sepic SB. Strength of isometric and isokinetic contractions. Phys Ther, 1980; 60(4): 412-419.

Norton K, Whittingham N, Carter L, Kerr D, Gore C, Marfell-Jones M. Measurement techniques in anthropometry. In: Norton K, Olds T, editors. Anthropometric. Sydney: University of New South Wales Press; 1996, p.25.

Pendergast DR, Mollendorf J, Logue C, Samimy S. Underwater fin swimming in women with reference to fin selection.Undersea Hyperb Med, 2003; 30(1): 75.

Stavrou V, Karatrantou N, Voutselas V, Stavrou St. Analysis of 200m surface finswimming. 15th International Congress of Physical Education \& Sport 2007, Komotini, Greece. Available from:

http://phyed.duth.gr/undergraduate/images/files/congress/20 07/congr_abs17.pdf

Vorontsov AR, Rumyantsev VA. Resistive forces in swimming. In: Zatsiorsky M. editor. Biomechanics in sport. Oxford: Blackwell Science; 2000. 